\title{
ATUAÇÃO DA EQUIPE DE ENFERMAGEM EM UNIDADES \\ DE SAÚDE DA FAMÍLIA NO \\ ATENDIMENTO À MULHER VÍTIMA DE VIOLÊNCIA
}

\author{
Joselito Santos $^{\alpha}$ \\ Maria Seleste Souza Silva Dantas ${ }^{b}$ \\ Luciana Araújo dos Reis ${ }^{c}$ \\ Stênio Fernando Pimentel Duarte ${ }^{d}$
}

\begin{abstract}
Resumo
A violência contra a mulher constitui um importante problema de saúde pública no Brasil e requer um conjunto de políticas articuladas que envolvam gestores e profissionais para o enfrentamento do problema em todo o território nacional. Neste sentido, o objetivo deste trabalho é identificar a atuação da equipe de enfermagem em Unidades de Saúde da Família no atendimento à mulher vítima de violência, a partir dos conhecimentos que possuem e de suas percepções em torno do problema. Foram incluídos 25 profissionais da equipe de enfermagem em USF da zona urbana de Vitória da Conquista - BA, os quais responderam a um questionário estruturado mediante consentimento informado. A maioria (92\%) dos profissionais considera a violência e violência contra a mulher $(80 \%)$ como temas de seu interesse, tendo $44 \%$ classificado a violência contra a mulher como um problema cultural; $52 \%$ afirmaram ter conhecimento sobre a política de proteção a mulher; $52 \%$ das profissionais reportaram casos de violência contra a mulher identificados em sua unidade de saúde, tendo a maioria (52\%) encaminhado a vítima para o aconselhamento. A maioria das profissionais (64\%) não integra a violência contra a mulher no planejamento e ações de assistência da unidade; $84 \%$ nunca realizaram cursos de capacitação e atualização em violência contra a mulher e $68 \%$ referiram haver dificuldades da equipe para lidar
\end{abstract}

a. Doutor em Ciências Sociais Docente. Pesquisador da Faculdade Independente do Nordeste. Núcleo de PósGraduação, Pesquisa e Extensão. Enfermeira. Doutora em Interunidades Saúde do Adulto Idoso. Docente Adjunta do Departamento de Enfermagem da Universidade Federal da Bahia/UFBA.

b. Concluinte do Curso de Enfermagem da Faculdade Independente do Nordeste (FAINOR).

c. Pós-Doutoramento em Saúde Coletiva/UFBA-ISC. Mestrado e Doutorado em Ciências da Saúde/UFRN. Especialista em Saúde Pública/Facinter. Especialista em Ativação de Processos de Mudança na Formação Saúde/ FiocruzDocente Titular/FAINOR. Coordenadora do Núcleo de Pesquisa/FAINOR. Coordenadora do Núcleo de Estudos e Pesquisa sobre Envelhecimento e Obesidade.

d. Doutor em Ciências pela Universidade do Estado do Rio de Janeiro (2006). Docente/Pesquisador da Faculdade Independente do Nordeste. 
com a violência contra a mulher. Em relação ao conhecimento sobre as leis, $36 \%$ nunca ouviram falar da Lei $n^{\circ} 11.340 / 2006$. Pela abrangência da legislação e pelo alcance que deseja ter para proteger as mulheres e acolhê-las no âmbito de uma política integrada e em rede, cabe aos profissionais de saúde e gestores de todos os níveis, maior empenho e articulação intersetorial para conhecer e efetivar essas leis.

Palavras-chave: Equipe de enfermagem; ESF; Lei; Política; Violência contra a mulher.

\title{
PRACTICE NURSING TEAM IN UNITS OF FAMILY HEALTH CARE TO WOMEN VICTIMS OF VIOLENCE
}

\begin{abstract}
Violence against women constitutes an important public health problems in Brazil, and requires a set of articulated policies involving managers and professionals to confront with the problem throughout the national territory. In this sense, the objective of this work is to identify the role of the nursing staff in the Family Health Units in assisting women victims of violence, from the knowledge they possess and their perceptions around the problem. 25 professional of nursing team were included at FHU of the urban area of Vitória da Conquista - BA, which answered a structured questionnaire through informed consent. The majority (92\%) of professionals considers violence and violence against women (80\%) as topics of interest, as $44 \%$ reported violence against women as a cultural problem, $52 \%$ said they were aware of the policy on protection women, $52 \%$ of professionals reported cases of violence against women identified on their health unity, with the majority (52\%) fowarding the victim for counseling. Most of the professionals (64\%) does not integrate violence against women in the planning and actions of assistance unit, $84 \%$ never made training courses and update on violence against women, and $68 \%$ reported having team's difficulties to handle violence against women. Regarding knowledge of the laws, $36 \%$ have never heard of Law 11.340/2006. By the scope of the legislation and the range they want to have to protect women and accept them as part of an integrated policy and network, it is for health professionals and managers at all levels, greater commitment and intersectoral processes to meet and carry out these laws.
\end{abstract}

Keywords: Nursing team; FHS; Law; Policy; Violence against women.

\section{PRACTIQUE EQUIPO DE ENFERMERÍA EN UNIDADES DE ATENCIÓN DE SALUD FAMILIAR A LAS MUJERES VÍCTIMAS DE LA VIOLENCIA}

\begin{abstract}
Resumen
La violencia contra las mujeres es un importante problema de salud pública en Brasil, y requiere un conjunto de políticas coordinadas que implican los directivos y profesionales para abordar el problema en todo el territorio nacional. En este sentido, el objetivo de este trabajo es identificar el papel del personal de enfermería en las Unidades de Salud de la Familia en la asistencia a las mujeres víctimas de la violencia, de los conocimientos que
\end{abstract}


poseen y sus percepciones de todo el problema. 25 equipo de enfermería profesional en la USF se incluyeron la zona urbana de Vitória da Conquista - BA, que respondieron a un cuestionario estructurado mediante la firma del consentimiento informado. La mayoría (92\%) de los profesionales considera que la violencia y la violencia contra las mujeres $(80 \%)$ como temas de interés, y el $44 \%$ violencia contra las mujeres denunciadas como un problema cultural, el $52 \%$ dijo que estaban al tanto de la política de protección las mujeres, el $52 \%$ de los profesionales informaron casos de violencia contra las mujeres identificadas en un centro de salud, con la mayoría ( $52 \%$ la remisión de las víctimas para el asesoramiento. La mayoría de los profesionales (64\%) no incorpora la violencia contra las mujeres en la planificación y las acciones de unidad de asistencia, el 84 \% nunca realizó cursos de capacitación y actualización sobre la violencia contra las mujeres, y el $68 \%$ informó tener dificultades para manejar el equipo la violencia contra las mujeres. Respecto al conocimiento de las leyes, el $36 \%$ nunca ha oído hablar de la Ley 11.340/2006. La amplitud y el alcance de la legislación que desea tener para proteger a las mujeres y aceptarlos como parte de una política integrada y de la red, es para los profesionales sanitarios y los gestores en todos los niveles, mayor compromiso y procesos intersectoriales para cumplir y llevar a cabo estos leyes.

Palabras clave: Personal de enfermeira; USF; Leyes; Política; Violencia contra la mujer.

\section{INTRODUÇÃO}

Os estudiosos consideram a violência como um fenômeno de grande complexidade e de difícil conceituação, a qual deve ser entendida como todo evento representado por negligências, ações, relações e omissões realizadas por grupos, classes, indivíduos e nações que causam danos emocionais físicos, morais ou espirituais. ${ }^{(1)}$

Violência é qualquer ação que pode vir a causar danos psicológicos, físicos, e morais contra outra pessoa ou coletividade. É uma questão de saúde pública devido às grandes implicações que causam à saúde humana desde uma lesão corporal ou agravo psicológico até a morte, sendo necessária a ação do setor da saúde que age no tratamento e prevenção desses agravos. ${ }^{(2)}$

Violência contra a mulher é definida como qualquer ato ou conduta que cause morte, dano ou sofrimento físico, sexual ou psicológico à mulher, tanto na esfera pública quanto na privada, conforme a Convenção Interamericana, que ficou conhecida como Convenção de Belém do Pará, de 1994, cujo objetivo central é Prevenir e Erradicar a Violência contra a Mulher. Por decorrência das discussões dessa convenção, a Lei Maria da Penha ${ }^{(2)}$ tornou-se o expoente da criminalização da violência contra a mulher desde 2006, pois prevê a punição para os agressores, algo não previsto antes da promulgação dessa lei.

A Política Nacional de Enfrentamento à Violência contra as Mulheres foi estruturada a partir do Plano Nacional de Políticas para as Mulheres (PNPM), elaborado com base na I Conferência Nacional de Políticas para as Mulheres, realizada em 2004 pela Secretaria Especial de Políticas para as Mulheres e pelo Conselho Nacional de Direitos da Mulher. O PNPM possui como um de seus eixos o enfrentamento à violência contra a mulher, que por sua vez, define como objetivo a criação de uma Política Nacional. Vale notar que a questão do enfrentamento a todas as formas de violência contra a mulher foi mantida como um eixo temático na II Conferência Nacional de Políticas para as Mulheres, realizada em agosto de 2007.(3)

Em 2006 o Brasil passou a contar com uma lei específica para coibir a violência doméstica e familiar contra a mulher Lei $n^{\circ}$ 11.340/2006 (Lei Maria da 
Penha) e com convenções e tratados internacionais como a Declaração Universal dos Direitos Humanos (1948), a Convenção Interamericana para Prevenir, Punir e Erradicar a Violência contra a Mulher (Convenção de Belém do Pará 1994), a Convenção sobre a Eliminação de Todas as Formas de Discriminação contra a Mulher (CEDAW, 1981) e a Convenção Internacional contra o Crime Organizado Transnacional Relativo à Prevenção, Repressão e Punição do Tráfico de Pessoas (Convenção de Palermo, 2000), que foi um avanço na luta feminista. ${ }^{(4)}$

Por conseguinte, a violência contra a mulher se constitui um importante problema de saúde pública no Brasil, e requer um conjunto de políticas articuladas que envolvam gestores e profissionais para o enfrentamento do problema em todo o território nacional. Neste sentido, o objetivo deste trabalho é identificar a atuação da equipe de enfermagem em Unidades de Saúde da Família no atendimento à mulher vítima de violência, a partir dos conhecimentos que possuem e de suas percepções em torno do problema.

\section{METODOLOGIA}

\section{TIPO DE ESTUDO}

Trata-se de estudo exploratório-descritivo, de campo, com abordagem quantitativa. A pesquisa exploratória tem como objetivo explorar aspectos de uma situação(5) e a descritiva objetiva descrever as características de determinada população ou fenômeno. ${ }^{(6)} \mathrm{O}$ estudo de campo focaliza uma comunidade e é desenvolvida por meio da observação direta das atividades do grupo estudado e de entrevistas com informantes para captar suas explicações e interpretações do que ocorre no grupo. O pesquisador realiza a maior parte do trabalho pessoalmente, pois é enfatizada a importância de o pesquisador ter tido uma experiência direta com a situação de estudo. ${ }^{(6)} \mathrm{Na}$ pesquisa de abordagem quantitativa os números se sobrepõem ao qualitativo, esperando-se do pesquisador que proceda a uma coleta de dados sistemática de informação numérica, sob condições de muito controle, cuja análise das informações coletadas devem ocorrer através de procedimentos estatísticos.

\section{UNIDADES DE OBSERVAÇÃO}

Segundo a Prefeitura Municipal de Vitória da Conquista, (7) o Programa de Saúde da Família está implantado desde 1998. Ao todo, são 38 equipes, sendo 23 na zona urbana e 15 na zona rural.

Cada uma dessas equipes é composta por médico, enfermeiro, odontólogo, auxiliar e técnico de enfermagem, auxiliar de saúde bucal e agentes comunitários de saúde. O objetivo do Programa de Saúde da Família é desenvolver ações de promoção e proteção à saúde do indivíduo, da família e da comunidade, prestando assistência integral, na unidade de saúde e no domicílio de forma contínua. O atendimento busca contemplar as necessidades de saúde da população e intervir sobre os fatores de risco aos quais a comunidade está exposta.

\section{TOTAL DE PARTICIPANTES E ESTRATÉGIA DE COLETA DE DADOS}

Foram incluídos 25 profissionais das equipes de enfermagem de 13 Unidades de Saúde da Família da área urbana de Vitória da Conquista, que responderam a um questionário estruturado, com questões objetivas envolvendo as seguintes dimensões:

Dimensão 1: dados da USF e do profissional; Dimensão 2: dados relativos ao funcionamento e às atividades da USF; Dimensão 3: dinâmica da assistência às mulheres vítimas da violência e procedimentos de notificação de casos. Dimensão 4: articulação intersetorial de assistência; Articulação integrada de assistência

\section{ETAPAS PARA A COLETA E ANÁLISE DOS DADOS}

A coleta de dados obedeceu a quatro etapas consecutivas: 
1. Recebimento da Certidão do CEP/FAINOR: os dados foram coletados após parecer favorável do Comitê de Ética em Pesquisa da Faculdade Independente do Nordeste (FAINOR), que emitiu uma Certidão específica autorizando o pesquisador a proceder a recolha das informações junto às instituições e sujeitos de pesquisa.

2. Contato com os profissionais: após a aprovação do protocolo de pesquisa pelo CEP/FAINOR, foi feito contato com os profissionais nas USF para explicar os procedimentos de pesquisa, momento em que foram agendados os dias e horários para a coleta de dados, que foram acordados conforme a agenda e disponibilidade dos mesmos.

3. Cenário de pesquisa e forma de abordagem: a abordagem foi feita no ambiente da Unidade de Saúde da Família onde o profissional trabalhava, em dias normais de atendimento.

4. Coleta de dados: os dados foram coletados após a anuência de cada sujeito, mediante a assinatura do Termo de Consentimento Livre e Esclarecido (TCLE), sendo aplicado, em seguida, o questionário, pelo pesquisador participante, previamente treinado pelo pesquisador responsável.

Consolidada a coleta, os dados foram lançados no Programa Microsoft Excel 2010, e analisados com o auxílio da estatística descritiva (média, frequência absoluta e frequência relativa), apresentados em tabelas e discutidos à luz da literatura pertinente.

\section{RESULTADOS}

Constatou-se no presente estudo que a maioria (92\%) dos profissionais considera a violência e violência contra a mulher $(80 \%)$ como temas de seu interesse, tendo $44 \%$ classificado a violência contra a mulher como um problema cultural.

A violência contra a mulher é de interesse coletivo e social, e deve interessar aos enfermeiros, por ser é um fenômeno presente em toda a sociedade, impactando a saúde pública de forma inegável, por conseguinte, exigindo práticas integradas desses atores em contexto de interação e habilidades profissionais com outras formações em saúde, pois este tipo de violência atenta contra os direitos humanos das mulheres.

A violência contra as mulheres constitui-se em uma das principais formas de violação dos seus direitos humanos, atingindo-as em seus direitos à vida, à saúde e à integridade física. A violência contra as mulheres em todas as suas formas é um fenômeno que atinge mulheres de diferentes classes sociais, origens, idades, regiões, estados civis, escolaridade, raças e orientação sexual. Por essas razões, é preciso que o Estado brasileiro adote políticas públicas acessíveis a todas as mulheres, que englobem as diferentes modalidades pelas quais a violência se expressa. Nessa perspectiva, devem ser também consideradas as ações de combate ao tráfico de mulheres, jovens e meninas. ${ }^{(8)}$

Nesta perspectiva é preciso combater a violência punindo os agressores, mas é preciso, sobretudo, evitar que a violência aconteça. Assim sendo, é preciso apoiar as mulheres que vivenciam a violência no processo de reconstrução de suas vidas. Também é necessário que elas tenham poder para mudar o rumo de suas histórias; que governos e a sociedade civil trabalhem juntos para mudar a cultura machista e patriarcal que justifica e estrutura a violência. Se o objetivo é construir uma cultura de paz e de respeito aos direitos humanos de todas as pessoas, esta construção começa em casa. ${ }^{(9)}$

A violência contra as mulheres não está confinada a uma cultura, uma região ou um país específico, nem a grupos de mulheres em particular dentro de uma sociedade. As raízes da violência contra as mulheres decorrem da discriminação persistente contra as mulheres. As mulheres que experimentam a violência sofrem uma série de problemas de saúde, e sua capacidade de participar da vida púbica diminui. A violência contra as mulheres prejudica as famílias e comunidades de todas as gerações e reforça outros tipos de violência predominantes na sociedade. ${ }^{(10)}$ 
Tabela 1 - Distribuição das profissionais quanto ao interesse sobre violência e violência contra a mulher. Vitória da Conquista/BA, 2013

\begin{tabular}{l|c|c}
\hline \multicolumn{1}{c|}{ INTERESSE SOBRE O TEMA } & N & $\%$ \\
\hline Violência é um tema do seu interesse & & \\
\hline Sim & 23 & 92,0 \\
\hline Não & 2 & 8,0 \\
\hline A violência contra mulher é um tema do seu interesse & 20 & \\
\hline Sim & 5 & 80,0 \\
\hline Não & & 20,0 \\
\hline A violência contra a mulher é um problema & 2 & \\
\hline Social & - & 8,0 \\
\hline Jurídico & 10 & - \\
\hline Saúde Pública & 11 & 40,0 \\
\hline Cultural & 2 & 44,0 \\
\hline Todas (Social+Jurídico+Saúde Pública+Cultural) & $\mathbf{2 5}$ & $\mathbf{1 0 0 , 0}$ \\
\hline Total & & \\
\hline Fonte: Dados da pesquisa 2013 &
\end{tabular}

Fonte: Dados da pesquisa. 2013.

$52 \%$ afirmaram ter conhecimento sobre a política de proteção à mulher, $100 \%$ afirmaram saber que a violência contra a mulher é de notificação compulsória; $52 \%$ reportaram casos de violência contra a mulher identificados em sua unidade de saúde, sendo os tipos mais comuns a violência moral (40\%) e psicológica (28\%), tendo a maioria $(52 \%)$ encaminhado a vítima para o aconselhamento.

A política de proteção à mulher alcança seu ápice com a Lei $n^{\circ} 11.340$, de 7 de agosto de 2006, conhecida como Lei Maria da Penha, considerada a mais abrangente proteção à mulher no contexto nacional e internacional, que se coaduna com a Política de Enfrentamento à Violência contras Mulheres, ${ }^{(8)}$ o Pacto de Enfrentamento de Violência Contra as Mulheres. ${ }^{(9)} \mathrm{O}$ Pacto e as ações nele propostas apoiam-se em três premissas: a) a transversalidade de gênero; b) a intersetorialidade; e c) a capilaridade. A transversalidade de gênero visa garantir que a questão de violência contra a mulher e de gênero perpasse as mais diversas políticas públicas setoriais. A intersetorialidade compreende ações em duas dimensões: uma envolvendo parcerias entre organismos setoriais e atores em cada esfera de governo (ministérios, secretarias, coordenadorias, etc.); e outra, implica uma maior articulação entre políticas nacionais e locais em diferentes áreas (saúde, justiça, educação, trabalho, segurança pública, etc.). Desta articulação decorre a terceira premissa que diz respeito à capilaridade destas ações, programas e políticas, levando a proposta de execução de uma política nacional de enfrentamento à violência contra as mulheres até os níveis locais de governo. ${ }^{(9)}$

A identificação e a notificação de uma violência constituem um caminho de proteção à vitima, que se sente mais acolhida e pronta para expor seu sofrimento. Concomitante a isso, o conhecimento dos instrumentos necessários para o atendimento das vítimas de violência contra mulher propicia ao profissional de saúde segurança e habilidade na condução dos casos, possibilitando melhorias na rede de atendimento e na saúde pública como um todo. (1) A notificação da violência doméstica pelos profissionais de saúde contribui para o dimensionamento epidemiológico do problema, permitindo o desenvolvimento de programas e ações específicos. ${ }^{\left({ }^{(2)}\right.}$

A lei $n^{\circ} 10.778$, de 24 de novembro de 2003 , estabelece a notificação compulsória, no território nacional, do caso de violência contra a mulher que for atendida em serviços de saúde públicos ou 
privados. Desta forma, a lei obriga essas instituições a notificar sobre os atendimentos que fizeram às mulheres que sofreram com este tipo de violência. Essa notificação é feita por profissionais de saúde das redes pública ou privada. Notificar faz parte de um conjunto de atividades, pactuado entre a Fundação Nacional de Saúde (FUNASA), Órgão Executivo do Ministério da Saúde, Secretarias Estaduais de Saúde (SES) e Secretarias Municipais de Saúde (SMS), relativos à área de epidemiologia e controle de doenças e agravos. ${ }^{(12)}$
Devido ao elevado índice de violência contra as mulheres no Brasil, a equipe de enfermagem, juntamente com outros profissionais de saúde, necessita prestar uma atenção voltada para a prevenção de todas as formas de violência contra as mulheres. Caso a violência já tenha ocorrido, a equipe multidisciplinar deverá ser capaz de atender às vítimas, com apoio e suporte que desperte confiança para haver a superação das angústias, vergonha, sentimentos de humilhação, medos e receios. ${ }^{(13)}$

Tabela 2 - Distribuição das profissionais quanto à identificação de casos de violência contra a mulher nas unidades de saúde. Vitória da Conquista/BA, 2013

\begin{tabular}{l|c|c}
\hline \multicolumn{1}{c|}{ IDENTIFICAÇÃO DOS CASOS DE VIOLÊNCIA } & N & $\%$ \\
\hline Conhecimento sobre a política de proteção a mulher & & \\
\hline Sim & 13 & 52,0 \\
\hline Não & 12 & 48,0 \\
\hline A violência contra a mulher é de notificação compulsória & & \\
\hline Sim & 25 & 100,0 \\
\hline Não & - & - \\
\hline Identificação de casos de violência contra a mulher na US & & \\
\hline Sim & 13 & 52,0 \\
\hline$\quad$ Não & 12 & 48,0 \\
\hline Total & $\mathbf{2 5}$ & $\mathbf{1 0 0 , 0}$ \\
\hline Fon
\end{tabular}

Fonte: Dados da pesquisa. 2013.

A assistência em enfermagem visa acolher de forma humanizada e atenciosa, através de medidas, posturas e atitudes dos profissionais de saúde na sua relação com a vítima. Deve ser uma assistência que busque ouvir com sensibilidade, criatividade e solidariedade, qualificando o cuidado. Sendo assim, a prática do acolhimento no trabalho de enfermagem deve ser pautada em atitudes humanizadas que se revelam no ato de receber, escutar e tratar. Por decorrência, deve repercutir na qualidade da assistência prestada. ${ }^{(14)}$

Para que haja uma abordagem à mulher violentada numa unidade de saúde, principalmente na atenção básica, é de suma importância estratégias de enfrentamento, as quais auxiliarão na transfor- mação do quadro, com vistas a reduzir a vulnerabilidade e a promover a saúde e o direito da cidadania, para que essas mulheres se sintam protegidas ao procurar o serviço de atenção básica. ${ }^{(15)}$

Quanto à violência como elemento da programação da equipe, a maioria das profissionais (64\%) não integra a violência contra a mulher no planejamento e ações de assistência da unidade; $84 \%$ nunca realizaram cursos de capacitação e atualização em violência contra a mulher. Das quatro profissionais que realizaram, $92 \%$ relataram ter ocorrido mudanças na assistência à muIher vítima de violência após a realização dos cursos; $68 \%$ referiram haver dificuldades da equipe para lidar com a violência contra a mulher. 
O fortalecimento da rede de atendimento passa pela ampliação dos serviços especializados e pela formação permanente dos agentes públicos, de modo a assegurar um atendimento qualificado e humanizado às mulheres em situação de violência e de evitar a revitimização destas nos serviços. A capacitação desses agentes constitui uma das ações prioritárias do Pacto Nacional pelo Enfrentamento à Violência contra as Mulheres, que tem investido, através de diferentes órgãos federais, especialmente a Secretaria de Políticas para as $\mathrm{Mu}$ Iheres, Ministério da Justiça, Ministério da Saúde, Ministério da Educação, Ministério do Desenvolvimento Agrário e Ministério do Desenvolvimento Social e Combate à Fome, na formação de diversos agentes, como juízes, promotores de justiça, profissionais da saúde, assistentes sociais, profissionais da segurança pública, professores da rede pública, gestores de políticas para as mulheres, da assistência social e da saúde, entre outros. ${ }^{(16)}$

De acordo com a Rede de Enfrentamento à Violência Contra as Mulheres, a capacitação da rede de atendimento também visa garantir a capilaridade do atendimento, ampliando o acesso das mulheres aos serviços. Uma das principais ações é a garantia de capilaridade, destacando-se a capacitação de profissionais da Assistência Social, especialmente aqueles dos Centros de Referência de Assistência Social (CRAS) e Centros de Referência Especializados de
Assistência Social (CREAS) de todo país na temática de gênero e de violência contra as mulheres. Estes serviços sócio-assistenciais estão distribuídos em quase todo território nacional, num total de 4.328 municípios com CRAS e 1.098 com CREAS. Os CRAS e CREAS foram priorizados entre os demais serviços sócio-assistenciais, os quais incluem abrigos para crianças e mulheres, casas de acolhimento provisório, casas-abrigo, entre outros, em função da proximidade desses serviços com a população de mulheres e por integrarem a rede de atendimento à mulher em situação de violência. Os CRAS constituem uma das portas de entrada para as mulheres em situação de violência, sendo responsáveis pelo encaminhamento e acolhimento das demandas das mulheres em situação de vulnerabilidade. Os CREAS são importante espaço de atendimento, podendo ser incorporados ao rol de serviços especializados. ${ }^{(16)}$

Toda mulher, independentemente de classe, raça, etnia, orientação sexual, renda, cultuar, nível educacional, idade e religião, goza dos direitos fundamentais inerentes à pessoa humana, sendo- Ihe asseguradas as oportunidades e facilidades para viver sem violência, preservar sua saúde física e mental e seu aperfeiçoamento moral, intelectual e social, ${ }^{(1)}$ sendo essas instituições supra mencionadas fundamentais para tanto.

Tabela 3 - Distribuição das profissionais quanto ao planejamento, cursos e dificuldades relativos à assistência à mulher vítima de violência. Vitória da Conquista/BA, 2013

\begin{tabular}{l|c|c}
\hline \multicolumn{1}{c|}{ PLANEJAMENTO, CURSOS E DIFICULDADES } & N & $\%$ \\
\hline $\begin{array}{l}\text { Violência contra a mulher no planejamento e ações de assistência da } \\
\text { unidade }\end{array}$ & & \\
\hline Sim & 9 & 36,0 \\
\hline Não & 16 & 64,0 \\
\hline $\begin{array}{l}\text { Existência de cursos de capacitação e atualização em violência contra } \\
\text { a mulher na unidade }\end{array}$ & & \\
\hline$\quad$ Nunca & 21 & 84,0 \\
\hline Às vezes & 4 & 16,0 \\
\hline Dificuldades da equipe para lidar com a violência contra a mulher & & \\
\hline Sim & 17 & 68,0 \\
\hline$\quad$ Não & 8 & 32,0 \\
\hline Total & $\mathbf{2 5}$ & $\mathbf{1 0 0 , 0}$ \\
\hline
\end{tabular}

Fonte: Dados da pesquisa. 2013. 
Em relação ao conhecimento sobre as leis e decretos que tratam da violência contra a mulher, $40 \%$ das profissionais relataram nunca ter ouvido falar da Lei $n^{\circ} 10.778 / 2003 ; 36 \%$ nunca ouviram falar da Lei $n^{\circ} 11.340 / 2006 ; 44 \%$ nunca ouviram falar do Decreto $n^{\circ} 7.958 / 2013 ; 32 \%$ nunca ouviram falar do Decreto $n^{\circ}$ 5.099/2003; 52\% conhecem o ligue 180.

Como se pode constatar, a falta de informação acerca dos instrumentos legais é um dos fatores que devem ser observados, quando se imagina que a ação eficaz em saúde da mulher violentada requer o domínio da legislação e dos marcos que regulam a política de proteção da mesma. Sem esse conhecimento a assistência e a orientação de que a mulher em situação de violência necessita ficam comprometidos.

Os principais instrumentos legais no atendimento da violência contra a mulher pelos profissionais de saúde é um tema pouco abordado por enfermeiros, embora seja um procedimento obrigatório e muito importante para a saúde pública. Apesar da existência de legislações específicas sobre o tema, há dificuldade na padronização das normas quanto aos Estados e Portarias diversas, que abordam o mesmo conteúdo tornando difícil o conhecimento do profissional sobre os programas complexos que estão inseridos. O preenchimento das fichas obrigatórias carece de explicações detalhadas, em algumas situações abordadas por manuais governamentais, porém descentralizados, em suas informações. Aspectos legais, emocionais, sociais e políticos necessitam de maior sincronismo e publicidade para que efetivamente se dê o cumprimento do previsto na Lei. ${ }^{(11)}$

A esse respeito, sobretudo o cumprimento à Lei $n^{\circ} 11.340 / 2006$, que cria mecanismos para coibir e prevenir a violência doméstica e familiar contra a mulher, apoiada nos termos do $\int 8 \circ$ do art. 226 da Constituição Federal, na Convenção sobre a Eliminação de Todas as Formas de Violência contra a Mulher, na Convenção Interamericana para Prevenir, Punir e Erradicar a Violência contra a Mulher e em outros tratados internacionais ratificados pela República Federativa do Brasil. Essa Lei dispõe sobre a criação dos Juizados de Violência Doméstica e Familiar contra a Mulher, bem como estabelece medidas de assistência e proteção às mulheres em situação de violência doméstica e familiar. ${ }^{(2)}$

No Art. $2^{\circ}$ da referida Lei, determina-se que toda a mulher, independentemente de classe, raça, etnia, orientação sexual, renda, cultura, nível educacional, idade e religião, goza dos direitos fundamentais inerentes à pessoa humana, sendothe asseguradas as oportunidades e facilidades para viver sem violência, preservar sua saúde física e mental e seu aperfeiçoamento moral, intelectual e social. No Art. $3^{\circ}$ determina-se o asseguramento das condições para o exercício efetivo dos direitos à vida, à segurança, à saúde, à alimentação, à educação, à cultura, à moradia, ao acesso à justiça, ao esporte, ao lazer, ao trabalho, à cidadania, à liberdade, à dignidade, ao respeito e à convivência familiar e comunitária. Para tanto, fica determinado que o poder público desenvolverá políticas que visem garantir os direitos humanos das mulheres no âmbito das relações domésticas e familiares no sentido de resguardá-las de toda forma de negligência, discriminação, exploração, violência, crueldade e opressão. Nesta perspectiva integrada de política, cabe à família, à sociedade e ao poder público criar as condições necessárias para o efetivo exercício dos direitos enunciados no caput. ${ }^{(2)}$ 
Tabela 4 - Distribuição das profissionais quanto ao conhecimento sobre as Leis e Decretos que tratam sobre a violência contra a mulher. Vitória da Conquista/BA, 2013

\begin{tabular}{|c|c|c|}
\hline LEIS E DECRETOS & $\mathbf{N}$ & $\%$ \\
\hline \multicolumn{3}{|l|}{ Lei $10.778 / 2003$} \\
\hline Não respondeu & 5 & 20,0 \\
\hline Lei no 10.778/2003 (nunca ouviu falar) & 10 & 40,0 \\
\hline Lei $n^{\circ} 10.778 / 2003$ (ouviu falar e sabe do que se trata) & 4 & 16,0 \\
\hline Lei no 10.778/2003 (ouviu falar e não sabe do que se trata) & 6 & 24,0 \\
\hline \multicolumn{3}{|l|}{ Lei 11.340/2006 } \\
\hline Não respondeu & 5 & 20,0 \\
\hline Lei $n^{\circ} 11.340 / 2006$ (nunca ouviu falar) & 9 & 36,0 \\
\hline Lei no $11.340 / 2006$ (ouviu falar e sabe do que se trata) & 4 & 16,0 \\
\hline Lei $n^{\circ} 11.340 / 2006$ (ouviu falar e não sabe do que se trata) & 7 & 28,0 \\
\hline \multicolumn{3}{|l|}{ Decreto $7.958 / 2013$} \\
\hline Não respondeu & 5 & 20,0 \\
\hline Lei no $7.958 / 2013$ (nunca ouviu falar) & 11 & 44,0 \\
\hline Lei n $7.958 / 2013$ (ouviu falar e sabe do que se trata) & 5 & 20,0 \\
\hline Lei $n^{\circ} 7.958 / 2013$ (ouviu falar e não sabe do que se trata) & 4 & 16,0 \\
\hline \multicolumn{3}{|l|}{ Decreto $5.099 / 2003$} \\
\hline Não respondeu & 5 & 20,0 \\
\hline Lei n 5.099/2003 (nunca ouviu falar) & 8 & 32,0 \\
\hline Lei n ${ }^{0} 5.099 / 2003$ (ouviu falar e sabe do que se trata) & 7 & 28,0 \\
\hline Lei nº 5.099/2003 (ouviu falar e não sabe do que se trata) & 5 & 20,0 \\
\hline Total & 25 & 100,0 \\
\hline
\end{tabular}

Fonte: Dados da pesquisa. 2013.

A propósito do conhecimento das leis e de uma prática efetiva a partir dos conhecimentos adquiridos ou não pelos profissionais, Ilha, Leal e Soares ${ }^{(17)}$ enfatizam que a mulher vítima de violência, quando procura o serviço de saúde, sente medo, vergonha e constrangimento em mostrar à origem de suas lesões. Por essa razão, a equipe de saúde têm que ter conhecimento e estar preparada para abordá-la, de forma adequada, de modo que essas mulheres admitam ter sofrido violência.

Pela abrangência da legislação e pelo alcance que deseja ter para proteger as mulheres e acolhê-las no âmbito de uma política integrada e em rede, cabe aos profissionais de saúde e gestores de todos os níveis, maior empenho e articulação intersetorial para efetivar essas leis, pois, como reflete Noberto Bobbio, ${ }^{(18)}$ temos muitas leis asseguradas, mas falta a sua efetivação a uma série de sujeitos sociais nas mais diversas faixas etárias e necessidades. É este um empreendimento dos mais difíceis, mas necessário.

\section{CONCLUSÃO}

É inegável o avanço da política de enfrentamento à violência contra a mulher e a forma como o estado tem desenvolvido nos últimos anos instrumentos legais que visem assegurar seus direitos e the oferecer proteção. Entretanto, observa-se que não há um acompanhamento de melhorias nas condições de assistência às mulheres que sofrem esse tipo de violência, seja pela falta de recursos humanos, materiais, físicos e financeiros, seja pela demora e falta de articulação inter e extra institucional, seja 
pela desarticulação intersetorial ou mesmo sua inexistência no interior da política de saúde.

Todavia, a identificação de problemas como o nível de conhecimento incipiente em torno da legislação de proteção à mulher e pouca participação em cursos de treinamento e capacitação, permitem identificar problemas locais para os quais são necessárias estratégias de solução. Essas dizem respeito a um maior engajamento em prol da meIhoria das condições de aquisição de conhecimento e de atuação dos profissionais nas unidades de saúde pesquisadas. Para tanto, a implementação de uma política local focada nos problemas prioritários locais pode assegurar melhorias a curto, médio e longo prazo através de estratégias de enfrentamento à violência contra a mulher, guiada pelos marcos regulatórios da política nacional, que devem ser adotados e ajustados à política local. Afora isso, estabelecer uma agenda contínua no campo da política de saúde visando a fomentar alternativas de serviços e implementação destes na realidade local para tornar mais visível o problema da violência contra a mulher, mobilizando o maior número de especialistas possível, que possam se articular em busca de soluções para modificar o panorama atual da assistência no município.

\section{REFERÊNCIAS}

1. Andrade CJM, Fonseca RMGS. Considerações sobre violência doméstica, gênero e o trabalho das equipes de saúde da família. Rev. Esc. Enferm. USP [Internet]. 2008 [Acesso em 2013 abr 8]; 42(3):591-5.Disponível em: http://www. scielo.br/pdf/reeusp/v42n3/v42n3a24.pdf

2. Brasil. Lei n. 11.340/2006. Coíbe a violência doméstica e familiar contra a mulher. 2006.

3. Brasil. Ministério da Saúde. Secretaria Especial de Políticas para as Mulheres. II Plano Nacional de Políticas para as Mulheres. Brasília; 2008.

4. Cordeiro AA, Fraga CK. A Lei Maria da Penha e a proteção legal à mulher vítima em São Borja no Rio Grande do Sul: da violência denunciada à violência silenciada. Serv. Soc. Soc. [Internet]. 2012 [Acesso em 2013 abr 2];110: 369-97.
Disponível em: http://www.scielo.br/pdf/sssoc/ n11O/aO8n110.pdf

5. Polit DF, Hungler BH. Delineamento de pesquisa em enfermagem. In: Polit DF, Hungler BH. Fundamentos de pesquisa em enfermagem. $3^{\mathrm{a} e d .}$. Porto Alegre: Artes Médicas; 1995.

6. Gil AC. Como elaborar projetos de pesquisa. $3^{a}$ ed. São Paulo: Atlas; 1991.

7. Vitória da Conquista. Programa de Saúde: confira a lista dos profissionais que atuam em Vitória da Conquista [Internet]. 2013. [Acesso em 2013 abr 24] Disponível em: http://www. pmvc.ba.gov.br/v2/noticias/programa-de-saudeda-familia-confira-a-lista-dos-profissionais-queatuam-em-vitoria-da-conquista

8. Brasil. Secretaria Nacional de Enfrentamento à Violência contra as Mulheres. Secretaria de Políticas para as Mulheres - Presidência da República. Política Nacional de Enfrentamento à Violência Contra as Mulheres. Brasília; 2011.

9. Brasil. Secretaria Nacional de Enfrentamento à Violência contra as Mulheres. Secretaria de Políticas para as Mulheres - Presidência da República. Pacto Nacional pelo Enfrentamento à Violência Contra as Mulheres. Brasília; 2011.

1O. Organização das Unidas. Una-se: Campanha do Secretário-Geral das Nações Unidas. América Latina pelo Fim da Violência Contra as Mulheres [Internet]. 2013 [acesso em 2013 nov 19]. Disponível em: http://www.onu.org.br/unase/ sobre/situacao/

11. Santinon EP, Gualda DMR, Silva LCFP. Violência contra as mulheres: notificação compulsória e outros instrumentos legais de uso dos profissionais de saúde. Âmbito Jurídico, Rio Grande. [Internet]. 2013 [acesso em 2013 nov 23]; 13(74). Disponível em: http://www.ambitojuridico.com.br/site/index.php?artigo_id= 7499\& n_link=revista_artigos_leitura

12. Saliba O. Responsabilidade d o profissional de saúde sobre a notificação de casos de violência doméstica. Rev. saúde pública [Internet] 2007. [acesso em 2013 maio 2]; 41(3): 472-7. Disponível em: http://www.scielo.br/scielo.php?script=sci_ arttext\&pid= So034-89102007000300021\&lng= pt\&nrm=iso

13. Moura MPB, Guimarães NCF, Crispim ZM. Rev. Enferm. Cent.-Oeste Min. 2O11; 1(4): 571-582. 
14. Morais SCRV, Monteiro CFS, Rocha SS. O cuidar em enfermagem à mulher vítima de violência sexual. Texto \& contexto enferm [Internet]. 2010 [acesso em 2013 mar 8]; 19 (1):155-60. Disponível em: http://www.scielo.br/pdf/tce/ v19n1/v19nla 18. pdf

15. Pedrosa CMA. A construção de uma ferramenta social para promoção da saúde e dos direitos das mulheres. Paideia [Internet] 2009. [acesso em 2013 fev 8]; 19(42):123-9. Disponível em: http://www.scielo.br/scielo.php?Script =sci_artte xt \&pid =SO 104-2902008000200008\&lng $=p t \& n r m=i s o$
16. Brasil. Secretaria Nacional de Enfrentamento à Violência contra as Mulheres. Secretaria de Políticas para as Mulheres - Presidência da República. Rede de Enfrentamento à Violência contra as Mulheres. 2011.

17. Ilha MM, Leal SMC, Soares JSF. Mulheres internadas por agressão em um hospital de pronto socorro:(in)visibilidade da violência. Rev. gaúcha enferm. [Internet] 2010. [acesso em 2013 mar 7]; 31(2): 328-34. Disponível em: http://www.scielo.r/pdf/rgenf/v3ln2/18.pdf

18. Bobbio N. A era dos direitos. Rio de Janeiro: Elsevier; 2004. 